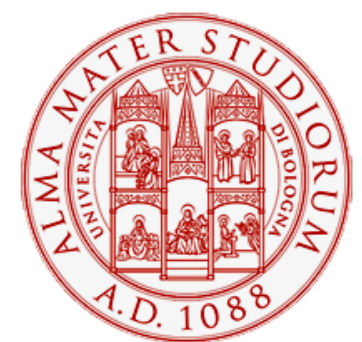

Alma Mater Studiorum - Università di Bologna DEPARTMENT OF ECONOMICS

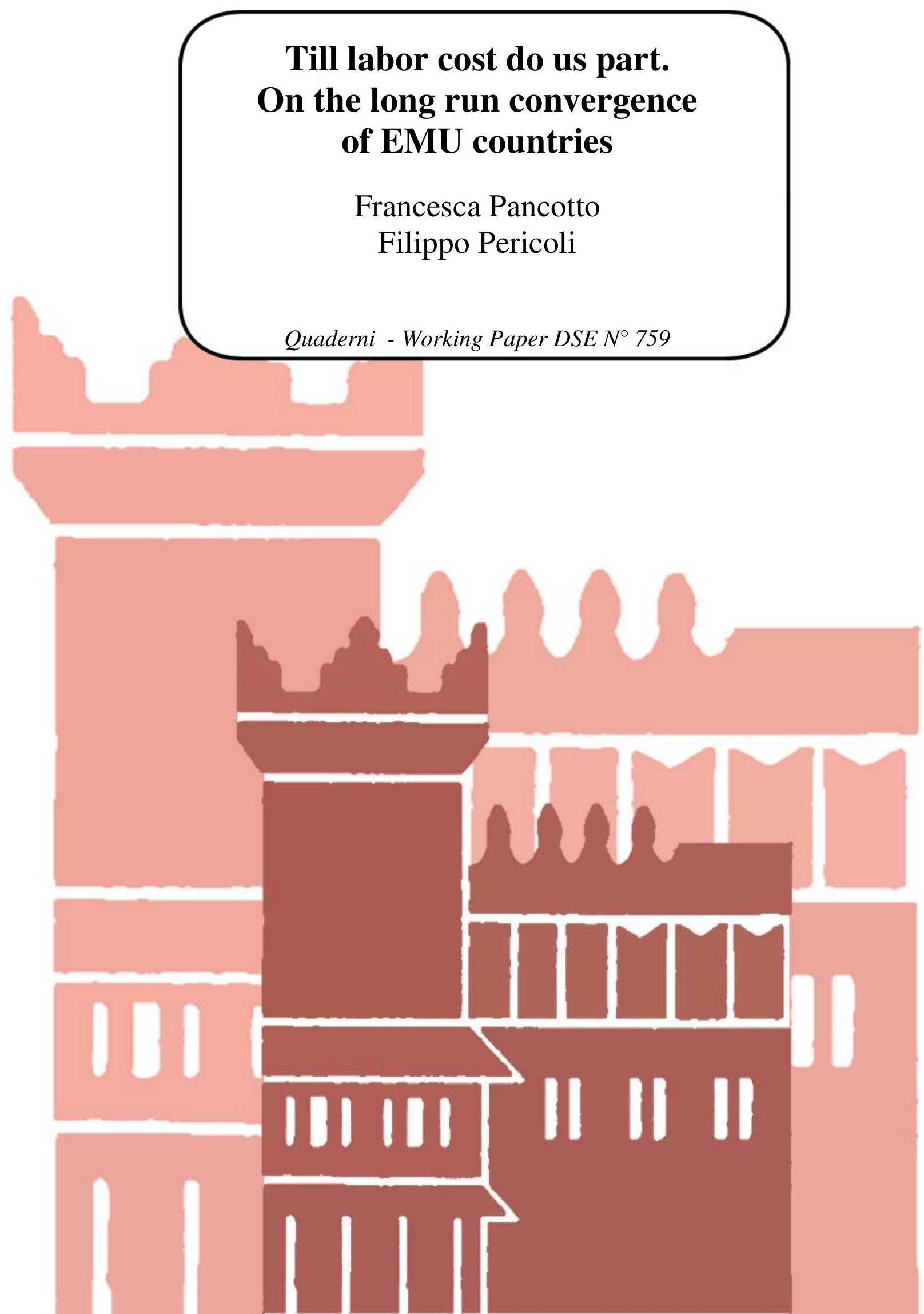




\title{
Till labor cost do us part. On the long run convergence of EMU countries
}

\author{
Francesca Pancotto, and Filippo Pericoli ${ }^{\dagger}$
}

June 7, 2012

\begin{abstract}
A sustainable long-run pattern in the relative competitiveness of euro area countries is a key factor for the survivorship of the monetary union. We analyze the issue focussing on unit labor cost dynamics using cointegration analysis for the whole economy and for the manufacturing sector separately. Our findings show that the introduction of the euro has increased, rather than decreased, the distance among member countries, as measured in the metric of unit labor costs. Dispersion of productivity rather than wage compensation suggests that persisting idiosyncratic dynamics are driven by real factors, i.e. diverging technological patterns rather than by monetary factors, expressed by wage compensation.
\end{abstract}

JEL codes: E31, O47, C32. Keywords: Unit labor costs, Convergence, Competitiveness, Manufacturing Sector.

June 7, 2012

\footnotetext{
${ }^{*}$ Corresponding author: francesca.pancotto@unimore.it, Department of Communication and Economics, University of Modena and Reggio Emilia, Viale Allegri, 9 , Reggio Emilia Bologna, Italy,

${ }^{\dagger}$ Department of Treasury of Italy's Ministry of Finance, Via XX Settembre 97, Rome, Italy and CEIS Economics Foundation of Tor Vergata University, Via Columbia 2, Rome, Italy
} 


\section{Introduction}

The sustainability of the monetary union is guaranteed in the long run if member countries converge in terms of relative competitiveness. Competitiveness indeed affects not only the rate of growth of a single member state but also the economic cohesion of the union, given the high level of interdependence associated to the single currency. Therefore it becomes essential to investigate over the existence of persistent divergences that might jeopardise its future. This fact has been largely recognized by the European Central Bank that has introduced a mechanism of systematic surveillance of member states competitiveness, with the aim of maintaining a common framework capable of identifying and correcting imbalances. Since 2007, the European Central Bank monitors the state of convergence of the member states by means of seven indicators of competitive gaps: current account deficits, ULC, the stock of a country's net external debt as a ratio to GDP, the rate of inflation, the current account deficit as a ratio to GDP, the private and government debt ratios, the stock of credit to the private sector (ECB, 2005, 2007). Any divergence of these indicators from the union average, is a signal that should be taken into account when evaluating sustainability. Our choice is to analyze unit labor costs (ULC thereafter), that measure the average cost of labor per unit of output: it informs on the relative dynamics of wages and productivity in the countries of the union and on the relationship among them. It represents a direct link between productivity and the cost of labor used in generating output. As it is an important and relatively stable component of inflation dynamics, with respect to more volatile determinants of inflation such as raw materials and commodity prices, it gives a long run idea on how wages inflation is steadily influencing the general price dynamics. In the perspective of a monetary union, the relationship between labor costs among member countries takes an even more important role as it expresses the degree of homogeneity, integration (and/or complementarity) of the member states. Bertola (2008) shows some concern related to the appropriateness of ULC as an indicator

of relative competitiveness of euro area members and wage dynamics, in particular in the comparison between tradable and non-tradable sector: his concerns are basically twofold. 
First, the comparability of data among member countries is affected by a low degree of homogeneity of data collection mechanisms; secondly, the Balassa-Samuelson effect can bias the information contained in the available data. Notwithstanding these issues, we believe that an inspection of the behavior of ULC for the total economy and the manufacturing sector, could give important insights on the dynamics of competitiveness of the currency union members. In a recent paper Dullien and Fritsche (2008) analyze ULC trends in the euro area with the aim to evaluate the degree of convergence reached within the euro area in terms of both wage and productivity trends. They first examine ULC developments before and after the introduction of the single currency and secondly compare the performance of euro area countries with other currency unions, namely the federal states in the United States of America and the Länder of the Federal Republic of Germany. They implement a cointegration approach on ULC growth rates and test convergence with respect to the union average. Their analysis finds cointegration and thus convergence of ULC but at the same time the comparison with the performance of the other currency unions is not in favor of euro area, where deviations from area-wide averages are much larger than in US regions as well as in German Länders. Moreover, it is of their concern, the presence of a tendency towards deviation in the last years of the sample, in particular for Germany.

Another contribution in this direction is the one of Tatierska (2008), which disaggregates ULC in 4 sub-sectors and uses quarterly data from 1990 up to the second quarter of 2007. She assesses cointegration mainly by means of Engle and Granger (1987) methodology and a panel Pedroni test (Pedroni, 1999), using euro area countries and comparing them with newly entered countries, namely Slovakia, Czech Republic, Poland, Ungary. She explores convergence by means of cointegration methodology of different economic sectors, but focusing on the convergence of newly entered countries with respect to the rest of the members. She finds evidence in favor of cointegration for almost all countries.

In this work, we extend these contribution in various directions. First, we investigate the existence of a long run relationship with the Johansen (1988) approach, which is more general than the Engle and Granger (1987) methodology implemented by Tatierska (2008) for various sectors. We verify cointegration with $\lambda$-max and Johansen trace tests between 
national ULC of each country and the area average. We also test the hypothesis of weak exogeneity of euro area ULC (excluded the i-th country) in the model for ULC for the generic i-th country: the rejection of this hypothesis would imply that the extent of disequilibrium in the i-th country affects the adjustment toward the equilibrium of ULC in the remaining euro area countries. Third, we verify whether the cointegrating vector has an economically desirable content, i.e. it is of the type $(1,-1)$ which would imply similar long-run growth of ULC growth rates and consequently a stable relative competitiveness relationship among the countries of the area. We also include tests of stability of parameters, as presented by Juselius (2006), based on the recursive likelihood on both the cointegration parameters and the feedback mechanisms. We also analyse the results of the estimates of the cointegrating vector, differently from Dullien and Fritsche (2008) which analyze instead mainly the loading factors as the main drivers of the adjustment process. Because of the low power of bivariate cointegration tests, we also performed panel cointegration tests, first Westerlund (2007) test in its normal version and in its modified version with bootstrapped critical values, in order to take into account cross section dependences. We also conduct the panel extension of the Johansen trace test proposed by Larsson et al. (2001) using both standard and bootstrapped critical values, simulated in order to correct the latter for cross-sectional dependence as well.

We perform the aforementioned analysis on both the whole economy and the manufacturing sector separately, departing from Dullien and Fritsche (2008) which only analyse ULC convergence of the total economy. We believe that exploring convergence of ULC in manufacturing sector increases profoundly the comprehension of the convergence of the european productive system, which is what ultimately matters in the understanding of the future sustainability of the union. Moreover, we analyse a different time span. Indeed, we preferred to give higher weights to the years following the monetary union, once the minimum number of observations required to ensure an appropriate inference was guaranteed. We believe that a sample of this sort would help in understanding more clearly the evolution of ULC in the last years and ultimately explore convergence in the light of the more recent evolution of economies the euro area. 
Finally, a work similar to our is a recent paper of Herwartz and Siedenburg (2011) which test convergence of inflation differentials in the monetary union using monthly relative normalized ULC indices for the manufacturing sector only from the IMF's international financial statistics, for Austria, Belgium, Finland, France, Germany, Ireland, Italy, and Spain. Similarly to ours, they use manufacturing sector data, interpreting ULC inflation differentials in this sector as a direct indicator of the relative evolution of external competitiveness within the monetary union. They test convergence for the years from 1979 to 2010 and then separately in two subsamples, before and after the monetary union.

The rest of the paper is organized as follows. In Section 2 we explore literature contributions related and relevant for our work. In Section 3 we describe the database used for the analysis with some preliminary statistical analysis and present the empirical methodology implemented in the following section. In Section 4 we report tests and estimates results. In Section 5 we draw some conclusions and policy implications.

\section{Literature Review}

In a seminal paper, Baumol (1986) explains how convergence in industrialized economies is achieved when innovation and investment in one country generates spillover effects on near-by countries. Countries at a lower level of development absorb part of the effects of innovation and increase their productivity, fostering income growth and wage increases. Innovation and investment spillovers generate such effect if technology is identical or at least comparable in all the countries involved in the process. Indeed, countries with a

lower technological advancement may not be completely capable to take advantage of these spillover effects and thus to catch up with the productivity advancements of the leader. The effects of this type of misalignment could be observed in the dynamics of labor costs, affected by productivity, by definition. If we hypothesize that tradable sector goods are more affected by innovation spillovers than non-tradable sector, we should observe a different behavior of the two labor costs when analyzed separately. Convergence in the tradable sector should consequently be more pronounced if the member countries are 
moving towards a similar technological pattern.

The existence of diverging technological patterns, could be explained by cumulative knowledge and increasing returns of scale driving innovation and technological change as in Arthur (1989). Indeed, countries characterized by a higher initial technological development, and/or knowledge advancement, would be already in a diverging path leading to a systematic better competitiveness performance, once the scope for beggar-thy-neighbor policies are removed, as it is the case for economies with a unitary monetary policy.

Krugman (1991) points at pecuniary external economies as the source of possible divergence among regions in a core-periphery model characterized by increasing returns in the manufacturing sector. Convergence or divergence would be determined by the elasticity of the manufacturing labor force with respect to wage. If the share of manufacturing workers decreases as the relative wage in the central region increases, the dynamics would be convergent. Indeed, workers will migrate out of the region with the larger work force. On the opposite, if the share of manufacturing workers in central region increases with its relative wage, workers will migrate into the region that already has attracted more workers, thus increasing the extent of divergence. In this case wages would be steadily higher in the economy with a larger manufacturing market. In the peripherical regions, in order to guarantee employment, it would be required a negative wage differential, that would be permanent.

The aforementioned theoretical contribution explains how the the comparison between tradable and non-tradable ULC can play an important role in signaling an eventual divergence between EMU countries.

Another channel of cross-country interaction might arise from the possibility that ULC increases in the non-tradable sector impact ULC in the tradable sector. Indeed, tradable goods are subject to higher degree of international competition and consequently adjust more strongly to shocks and fluctuations from international markets. Non-tradable sectors instead, can benefit from a more protected price dynamics and consequently have guaranteed a higher average level of wages. Salido et al. (2005) explore determinants and macroeconomic implications of persistent inflation differentials in Spain within EMU. They 
show that aggregate demand for non-tradable goods and real-wage rigidities are crucial in explaining diverging price developments in Spain. This is due to the fact that ULC in non-tradable sector affect productions costs of tradable goods and reduce competitiveness in the tradable sector as well.

Relatedly, Zemanek et al. (2010) investigate over the persistency of intra-EMU current account deficits. In particular, they assess the impact of structural reforms in the public and the private sector onto current account balance. They find that current account divergences may have been generated by inflationary pressures originating in the non-tradable sector. Non-tradable goods are used as inputs for tradable goods, thus influencing the price of tradable goods as well; moreover, wages in the manufacturing sector would imitate wage increases realized by workers employed in the service sector (where wages are more rigid). They call this mechanism reversed Balassa-Samuelson effect, "... where rising wages in the non-tradable sector trigger wage adjustment in the traded goods sector, which might reduce the current account balance (Zemanek et al., 2010)."

In a different dimension, the comparison between tradable and non-tradable ULC, are relevant in the debate on the impact of wage developments in the public sector onto convergence. Public sector wages account on average for more than $10 \%$ of GDP and more than $20 \%$ of total compensation of employees. Clearly, public wage increases constitute a strong signal for private sector wage negotiations: the larger the public sector is, compared with the tradable sector, the stronger will be the signal. Hence, the larger the public sector, the more important, and the more challenging, will be its role in the overall evolution of cost competitiveness (Trichet, 2011). Empirical evidence supports the idea of the relevance of public sector wages in driving private wage-agreements in many euro area countries. Such spillovers seem to be particularly important in countries that have experienced high and volatile public wage growth. Other analyses confirm the public sector wages may be responsible for rapid increases in ULC and misaligned intra-euro area competitiveness (Perez and Sanchez, 2010; Lamo et al., 2008). 


\section{Data and Methodology}

\section{Data}

The analysis has been restricted to those countries adhering to the European Monetary Union since its beginning, (January the 1st, 1999): Austria, Belgium, Finland, France, Germany, Ireland, Italy, Luxembourg, Netherlands, Portugal and Spain. We included in the dataset also Greece that joined the union two years later, on January 1st 2001 and used data from 1980 to today. This choice has been dictated by the aim of considering a set of countries homogeneous with respect to the duration of their participation to the currency union.

The empirical analysis has been performed at yearly frequency on the basis of national accounts data extracted from Ameco, the on-line database by the European Commission. Our analysis focuses on ULC figures for the whole economy and for the manufacturing sector. For the total economy we have computed average ULC as compensation of employees divided by gross domestic product at constant prices, while for the manufacturing sector ULC figures have been obtained as the ratio of sectoral compensation of employee to sectoral value added at constant prices $^{1}$.

For the years preceding the adoption of euro, both variables, originally expressed in national currencies, have been converted in ecu units by means of the nominal bilateral exchange rate of national currencies versus ecu. ${ }^{2}$

The key point of the empirical analysis consists in the comparison of ULC in the i-th country of the euro area with ULC in the remaining countries. Thus, for every country of the sample we have computed average ULC figures in the remaining countries by removing from the average the i-th country ULC. Indeed, especially in the case of big countries such as Germany, France or Italy, a comparison with euro area average (i-th country in-

\footnotetext{
${ }^{1}$ Ameco database. Compensation of employees (code UWCD); gross domestic product at constant prices (code OVGD); sectoral compensation of employees (code ISIC D UWCM); sectoral value added at constant prices (code ISIC D OVGM).

${ }^{2}$ Ameco database (code: XNE).
} 
cluded) would produce a biased picture of real underlying dynamics. All variables have been converted in logarithms to attenuate heteroskedasticity and to allow a simple economic interpretation for the estimated parameters, namely elasticities instead of partial derivatives. We define $U L C$, as:

$$
U L C=\frac{C E}{Y}
$$

where $C E$ is nominal compensation of employees and $Y$ is real gross domestic product. Dividing and multiplying equation (1) by total employment $(E)$ and by number of employees $\left(E^{d}\right)$, ULC reads:

$$
U L C=\frac{E^{d}}{E} \frac{C E / E^{d}}{Y / E}=\bar{k}^{d} \frac{W^{d}}{Q}
$$

where $Q=Y / E$ is average labor productivity, i.e.real output per person employed, $W^{d}=C E / E^{d}$ is average compensation per employee and $\bar{k}^{d}$ is the ratio of employees to total employment. Assuming $\bar{k}^{d}$ constant, changes in ULC are driven by two components: the wage component, expressed by unitary wages, and the technological component, approximated by labor productivity.

Relatedly to this decomposition ${ }^{3}$, we can state that if the ULC in the two countries diverge, either the two countries are moving on different technological patterns or employees are not being paid similarly because of different bargaining policies or different degrees of nominal rigidities. Which of the two components actually matters for the hypothesized divergence is not irrelevant: in particular, a productivity diverging dynamics would signal a structural and long-run imbalance in the growth capacity of the lesser productive country. This element would be even more relevant for the manufacturing sector which represents the core of a country productive system.

We explore the evolution of ULC in the euro area countries compared with the union average in Fig. 1. Austria, Belgium, France, Luxembourg and Netherlands show a pattern

\footnotetext{
${ }^{3}$ Rearranging (2), the growth rate of $U L C$ reads:

$$
U \dot{L} C=\dot{W}^{d}-\dot{Q},
$$
}


that is substantially in line with the euro area, while a different picture emerges for the remaining countries. Finland, has a converging pattern from 1995 on, while before that date, values were substantially over the mean. Italy, Ireland and Greece show a level persistently below the euro area, while Spain and Portugal reach the area average around year 2000. Southern-peripherical countries show a lower level but a faster rate of growth of ULC than central-northern economies.

With regards to the manufacturing sector (see Figure 2), figures are slightly different. Austria and the Netherlands, have benefited of substantial competitiveness gains, showing a reduction in the rate of growth of ULC in the years following the union. Portugal and Spain show a positive trend in a dynamics of catching up with the union average as in the case of the total economy, but showing as well a slight tendency to converge. The same can be told for Greece whose fast increase speeds up after 2005 and overcomes the union average. On the opposite, with the participation to the common currency area Germany has improved its relative competitive position in the manufacturing sector. The striking picture is the one of Ireland that presents a negative trend of manufacturing ULC from the eighties onward. To appreciate more precisely the difference between the dynamics of total economy and manufacturing sector ULC in Figure 3, we compared the two figures calculating the ratio of a country ULC over its euro area average. Again, Belgium, Netherlands, France and Austria present an ULC evolution very similar in the total economy and the manufacturing sector; Greece, Spain and Portugal as well, but with a clear increasing trend, for Portugal in particular beginning from the nineties. Italy presents a diverging pattern of ULC of manufacturing and total economy starting from the end of nineties and increasing after the union. Finland and Ireland present a drop in ULC of manufacturing sector on the contrary.

The variability of behavior of ULC of the member countries can be appreciated in Figure 4 where we calculate the coefficient of variation among member countries ${ }^{4}$, for ULC, productivity and wage compensation, productivity and compensation defined as in

\footnotetext{
${ }^{4}$ Figures for productivity and wage compensation where available separately only from 1990 onwards
} 
Eq. 2. The dynamics is clear: ULC diverges consistently for the manufacturing sector and with an increasing trend which is steeper for the last years. This result is partially different from the one of Herwartz and Siedenburg (2011) which finds a reduction in volatility of ULC in manufacturing sector in the years following the currency union. Their dataset is however limited to 2009, and uses a smaller dataset, including only the 8 out of the 12 of the countries included in our sample ${ }^{5}$. On the contrary, our result is in line with Fischer (2007) which uses our same sample of countries. Total economy variability is milder but still increasing in the very recent years (following 2008). Exploring the components of ULC as in the second and third table of Figure 4, we observe how the component driving the diverging pattern of ULC in member states is mainly productivity. The wage component instead is converging, and strongly for the manufacturing sector. The divergence of the dynamics of productivity among member countries reflect potential different patterns of specialization in the countries productive system. It is compatible with theories supporting non-homogeneous diffusion of technology among countries.In the rest of the paper, we are going to explore convergence of the member countries more accurately with the use of a cointegration analysis.

\section{Methodology}

The first step of our analysis consists in the identification of univariate properties of ULC time series, within the considered timespan. Univariate ADF tests indicate that almost all ULC time series included in the analysis are not stationary, but it suffices to differentiate them once to achieve stationarity ${ }^{6}$. The finding that ULC series are I(1) allows us to specify a VECM model for the level of the variables. We investigate over the existence and the shape of long run stable economic relationships within the multivariate approach to cointegration by Johansen (1988) and Johansen and Juselius (1990). The main advantage of this framework is that it provides likelihood-ratio based tests for identifying

\footnotetext{
${ }^{5}$ They analyse the following countries: Austria, Belgium, Finland, France, Germany, Ireland, Italy, Spain.

${ }^{6}$ Results of these tests are available from the authors upon request.
} 
the cointegration rank which characterizes any arbitrary set of endogenous variables. The size and the power of these tests are not optimal in small samples, when the asymptotic distributions are generally poor approximations to the true distributions (Juselius, 2006). We apply this method to a sample of 32 observations for the economy as a whole (years 1980-2011) and for the manufacturing sector (years 1979-2010). Even if this is not a large sample in terms of number of observations, there is a number of facts which make our analysis robust to small sample biases. Shiller and Perron (1985) have proven that when investigating over long run relationship the timespan considered is more relevant than the frequency of observations, which means that a sample of $N$ yearly observations is more informative than a sample of $N$ quarterly observations. The validity of this finding has been extended by Wanhong (1996), who shows, by means of Monte Carlo simulations, that the performance of the test is better the longer the timespan considered. Moreover, Gonzalo and Pitarakis (1999) have shown that, for a given sample size, the performance of the cointegration test is better the lower the dimensionality of the system which in our case is only two. Lastly, the results of the tests on the cointegration rank as well as on the restrictions to the cointegrating vectors remain valid ${ }^{7}$ even with the small sample Bartlett correction proposed by Johansen (2002).

We test the existence of a stable cointegration relationship between ULC in the i-th country and in the euro area (excluded the i-th country) by means of a two equations model that we present in the following. Let us consider the bi-dimensional VAR model:

$$
\begin{aligned}
& \mathbf{X}_{\mathbf{t}}=\phi+\mathbf{A}_{\mathbf{1}} \mathbf{X}_{\mathbf{t}-\mathbf{1}}+\ldots+\mathbf{A}_{\mathbf{k}} \mathbf{X}_{\mathbf{t}-\mathbf{k}}+\epsilon_{\mathbf{t}}, t=1, \ldots, T \\
& \epsilon_{\mathbf{t}} \sim I N_{2}(\mathbf{0}, \boldsymbol{\Omega})
\end{aligned}
$$

where $\mathbf{X}_{\mathbf{t}}$ is a $2 \mathrm{x} 1$ vector including the logarithm of ULC for the $\mathrm{i}$-th country and for the euro area, $\mathbf{A}_{\mathbf{i}}$ is a generic $(2 \mathrm{x} 2)$ matrix of parameters $(i=1, \ldots, k) ; \phi$ is a vector of constants and $\epsilon_{\mathbf{t}}$ is the error component of the model that is assumed to follow a bivariate normal distribution. Juselius (2006) shows that if the variables included in the system are integrated of order one, allowing for the presence of deterministic components, the model

\footnotetext{
${ }^{7}$ Results unreported, available on request.
} 
can be re-parametrized as:

$$
\Delta \mathbf{X}_{\mathbf{t}}=\alpha\left(\beta^{\prime} \mathbf{X}_{\mathbf{t}-\mathbf{1}}\right)+\mu_{0}+\mu_{1} t+\Gamma_{1} \Delta \mathbf{X}_{\mathbf{t}-\mathbf{1}}+\ldots \Gamma_{k-1} \mathbf{X}_{\mathbf{t}-\mathbf{k}+\mathbf{1}}+\epsilon_{t}
$$

where the product $\beta^{\prime} \mathbf{X}_{\mathbf{t}-\mathbf{k}}$ is a vector of stationary cointegration relations which describe the long run behavior of the system. The number of cointegrating vectors can be identified from the rank of the matrix $\Pi=\alpha \beta^{\prime}$, by means of likelihood ratio-based maximum eigenvalue $(\lambda$-max $)$ and trace tests.

A priori it is not known whether there are linear trends in some of the variables, or whether they cancel out in the cointegrating relations or $\operatorname{not}^{8}$. Five different models arise from different restrictions on the deterministic components of Eq. (5). From the inspection of time series we can clearly exclude from the analysis those models which assume no linear trend in the data (two out of the five models proposed by Juselius (2006)). Moreover we can also exclude a model with a linear trend in the differenced variables, i.e. with a quadratic trend in data. Thus there remain two type of models available for the analysis. In the first type of model (model 1 thereafter) we include a constant in the VAR model in differences, a formulation which allows for a linear trend in data but without a trend in the cointegrating space. The other model available (model 2 thereafter) includes not only a constant in the VAR model in differences and thus a linear trend in data, but also a linear trend in the cointegrating space. The lag length of the VAR model has been chosen on the basis of the Schwartz Information Criterium which almost always indicates an optimal lag of one for the VAR model in levels ${ }^{9}$, which corresponds to an optimal lag of order zero for the model in the VECM representation. Given the aforementioned restrictions, the specification adopted in our empirical analysis, from Eq. (5), becomes :

$$
\Delta \mathbf{X}_{\mathrm{t}}=\alpha \beta^{\prime} \mathbf{X}_{\mathbf{t}-\mathbf{k}}+\mu_{\mathbf{0}}+\boldsymbol{\Gamma}_{\mathbf{1}} \Delta \mathbf{X}_{\mathbf{t}-\mathbf{1}}+\epsilon_{\mathrm{t}}
$$

Cointegration analysis can be interpreted as a convergence test with some limitations: first, a country being on a catching up path might result in non-cointegrated series being

\footnotetext{
${ }^{8}$ See Juselius (2006) for a detailed description.

${ }^{9}$ Data available upon request to the authors.
} 
nonetheless on a fruitful pattern. With respect to this point, what we are interested in whether the countries are moving on a common path or trying efforts in that direction, independently from the positive or negative trend of such path. Clearly, the desired outcome of policy makers would be that countries converge towards a common and fruitful dynamicsSecondly, cointegration tests are sensitive to the particular sample considered. Indeed, we decided to employ yearly data for the timespan 1980-2011 for the total economy, 1979-2010 for the manufacturing sector. This is a rather homogeneous period, approximatively coincident with the 'great moderation'(Stock and Watson, 2002). This is indeed a period characterized by a relatively stable macroeconomic environment, and at the same time it guarantees a minimal number of yearly observations for applying the Johansen's methodology and estimating the cointegrating vectors in a bidimensional system.

\section{Results}

\section{Cointegration tests}

The first step of the analysis consists in determining the cointegrating rank of the bidimensional system constituted by ULC in the i-th country and ULC in the rest of the euro area. In our case, the cointegrating rank can be 0,1 or 2 . The only economically interesting case is that of a system with rank equal to 1, which means that even though both series are non-stationary, there exists a linear combination of the two variables which is stationary (or trend-stationary). In our case, the presence of a system of rank 1, would imply a long

run and stable, equilibrium relation between ULC in the i-th country and the rest of the euro area.

The results of the sequential testing procedure proposed by Johansen and Juselius (1990) of the trace and $\lambda-\max$ cointegration tests are reported in Table 1 . For the total economy, the trace and the maximum eigenvalue statistics indicate that there exists cointegration in all the countries included in the sample, at 5\% significance level.

For Austria, France, Germany, Greece, Ireland, Luxembourg, Netherlands, Portugal 
and Spain we accept the hypothesis of cointegration even without a linear trend in the cointegrating space, while in the case of Belgium, Finland and Italy it is necessary to include a linear trend in the long run behavior of the system to achieve cointegration.

As Table 2 shows, the results for the manufacturing sector are less favorable. We have excluded Luxembourg due to a high number of missing observations. With regards to the remaining countries, we accept the hypothesis of cointegration for Austria, Belgium, France, Germany, Greece, Ireland, Italy, Netherland and Spain, while in the case of Finland and Portugal we reject it. In detail, there is cointegration without a linear trend in the cases of Austria, Belgium, Greece, Ireland, Italy and Spain, while in the cases of France, Germany and Netherlands we included a linear trend in the cointegrating space to achieve cointegration. The existence of a statistical cointegrating relationship cannot be considered as a proof of sustainability because the shape of the cointegrating space may economically unsustainable in the long run. The presence of a trend in the cointegrating space is economically relevant in the analysis of the convergence because it implies that the trajectories are systematically diverging. In other words, the cointegration analysis may be regarded as a test of sustainability only under very special assumption on the values of the parameters of the cointegrating vector.

\section{Cointegrating vectors}

In this section we explore the parameters of the cointegrating vectors previously estimated. In order to facilitate the reading of our findings, we rewrite Eq. (6) in scalar form. Let us define $u l c_{i, t}$ the logarithm of ULC in the i-th country at date $\mathrm{t}$ and by $u l c_{e m u_{-i}, t}$ the logarithm of ULC in the remaining countries of the euro area. Equation (6) can be rewritten as:

$$
\begin{aligned}
\Delta\left(u l c_{i, t}\right)= & \alpha_{11}\left(\beta_{11} u l c_{i, t-1}+\beta_{12} u l c_{e m u_{-i}, t-1}+\beta_{13} t+\beta_{14}\right) \\
+ & c_{11} \Delta\left(u l c_{i, t-1}\right)+c_{12} \Delta\left(u l c_{e m u_{-i}, t-1}\right)+c_{13}+\epsilon_{1, t} \\
\Delta\left(u l c_{e m u_{-i}, t}\right)= & \alpha_{21}\left(\beta_{11} u l c_{i, t-1}+\beta_{12} u l c_{e m u_{-i}, t-1}+\beta_{13} t+\beta_{14}\right) \\
& +c_{21} \Delta\left(u l c_{i, t-1}\right)+c_{22} \Delta\left(u l c_{e m u_{-i}, t-1}\right)+c_{23}+\epsilon_{2, t}
\end{aligned}
$$


The first element to consider is the evaluation of the sign and the value of the coefficient $\beta_{12}$. A negative sign for this coefficient suggests that in the long run there exists a positive loglinear function which links ULC in the i-th country with ULC in the euro area considered as a whole. Secondly, this relationship is stable and converging, the more this coefficient is close to -1 . On the contrary, the country would be on a systematically diverging path. The significance of a deterministic trend in the cointegrating vector may cast some doubt over the economic sustainability of the observed dynamics. A stable relationship up to a deterministic trend in the cointegrating vector would imply a stable diverging dynamics in ULC dynamics between one country ULC and the rest of the area.

Table 3 reports the cointegrating vectors obtained from the reduced rank estimate of the VECM models normalized on ULC in the i-th country. As regards the estimates conducted for the total economy, results show that in all cases the coefficients have the right negative sign. Indeed, Germany and Austria are characterized by a stable tendency toward a relative decrease of ULC as their estimates for the coefficient $\beta_{12}$ are smaller than one. Luxembourg, Netherlands and Spain have a diverging pattern but less pronounced than that of France Greece, Ireland and Portugal, for which the coefficient is way above 2. Finally the parameter estimates for Belgium, Finland and Italy are not directly comparable in terms of relative competitiveness due to the presence of a significant parameter for the linear trend in the cointegrating space. This suggests that these three countries have the most diverging dynamics out of the countries of the area.

The results are different in the case we consider relative ULC dynamics in the manufacturing sector alone. In this case we find that Austria, Germany and Ireland are characterized by a cointegrating vector with the wrong 'positive' sign: the higher ULC in euro area, the lower in these two countries. Germany and Austria exhibit a stable tendency toward increasing their relative competitiveness, which is positive for the future of their manufacturing sector, but relatively negative in terms of considering convergence with respect to the rest of the union. The positive sign of the coefficient that we observe fore Ireland $\beta_{12}$ is in line with the substantial divergence of the productive system of this country from the rest of the union, which is also well visible in the panel of Fig. 3 related to Ireland. 
In the case of France and the Netherlands, the cointegrating vector shows a negative and lesser than one coefficient, which means that they are in a converging and stable path with respect to the euro area, notwithstanding the presence of a significant trend in the cointegrating space whose coefficient is nonetheless trascurable in value. For what concerns Italy, ULC in manufacturing sector appears to converge more than ULC in total economy: the cointegrating vector shows the 'right' negative sign even though the coefficient is larger than one. This confirms what can be observed in Fig. 3 in the panel related to Italy: the ratio of italian ulc over euro area is approaching one for the manufacturing sector, while the same does not happen for total economy. This results may be explained by a catching up pattern that italian manufacturing system has been experiencing after the introduction of the euro thanks to the internationalization of italian productive system. A 'correct negative' sign of the coefficient $\beta_{12}$ is present for Belgium and Spain as well, but for these two countries, the evolution of ULC for manufacturing sector and total economy are similar, as it can be seen again from Fig. 3 and can be confirmed from the similar results in terms of cointegrating vector estimates of the total economy (See in the top panel 3. Lastly, we denote the lack of a stable cointegrating relationship in the manufacturing sector ULC for Finland and Portugal: for these two countries it is not even possible to identify a stable

relationship with the rest of the area - not even diverging. In the case of Luxembourg we cannot perform the estimation as data available are not sufficient to perform a robust cointegration analysis.

\section{Weak exogeneity tests}

After having estimated the VECM models for the total economy and for the manufacturing sector, we proceeded to test some economically relevant hypothesis starting from the unrestricted version of the models. First we have conducted a test of weak exogeneity by verifying the likelihood of the assumption that, in the equation for ULC dynamics in the euro area, the loading factor of disequilibrium in the i-th country is equal to zero, i.e. we test that $\alpha_{21}=0$, in Eq. (7). The results of the tests (table 4 ) imply that the 
hypothesis of weak exogeneity is always rejected by the data for the total economy as well as for the manufacturing sector alone. This result may seem counterintuitive in a normal setting given that one generally expects that a small country such as Ireland or Belgium should not affect ULC dynamics of a big country such as Germany. However, our model is deliberately not structural as our goal consists in examining long run tendencies in ULC dynamics rather than understanding real data generating processes. This means that the rejection of the hypothesis of weak exogeneity should not be regarded as an evidence of the economic importance of a given country. Rather we believe that there may exist common factors which drive ULC dynamics in small as well as in big countries and that these factors render ULC dynamics in the remaining euro-area countries error-correcting with respect to disequilibrium of a given country. This result justifies the adoption of the multivariate approach to cointegration by Johansen (1988), ruling out the possibility of conducting inference within the Engle and Granger's (1987) univariate framework.

\section{Relative convergence tests}

We have also tested the hypothesis that the $\beta$ in Eq. (6) vector is of the type $(1,-1)$, which means that the elasticity of ULC in the i-th country with respect to ULC in the area is unitary. From an economic point of view this means that the relative competitiveness of a given country with respect to the euro average is constant in the long run. Notwithstanding some limitations this test can be assimilated to a test of economic sustainability, for a given country, of the adhesion to the currency union. From the results of the test reported on table 5 it emerges that the hypothesis of relative convergence is always strongly rejected by the data. This means that even if we did find a stable statistical relation between country i and euro area ULC, the shape of the cointegrating vector is such that euro area countries exhibit tendency to diverge in terms of relative competitiveness. These diverging dynamics may produce unsustainable effects on intra-area trade balances and resource allocations given that ULC represent the most important factor driving producer prices. 


\section{Parameters constancy}

We have assessed the stability of estimated parameters over the timespan considered, performing the test based on the recursive log likelihood function in the X-form, as described in Juselius (2006). With regards to the total economy (see Figure 5), the tests indicate that estimated parameters are substantially constant over time in ten out of the twelve countries considered, the only exceptions being Italy and Ireland. On the opposite, in the manufacturing sector, the tests reveal that for all nine cases (see Figure 6) where we have found cointegration, the parameters suffer from non constancies and thus measure only average effects (Juselius, 2006). In detail, it emerges that the models for the manufacturing sector have been rather volatile at the beginning of the 1990s and at the beginning of the 2000s, after the introduction of euro.

\section{Panel cointegration tests}

In this section we verify the existence of a cointegration relationship among the countries of our sample by means of a panel cointegration test procedures: they allow indeed the analysis of both the time-series and the cross-sectional dimension of the dataset.

First, we conducted the four standard residual-based panel cointegration tests proposed by Westerlund (2007) in the version with standard critical values and the one with bootstrapped critical values, which are implemented when cross-sectional dependency is suspected. The null hypothesis of residual based panel cointegration tests (Westerlund, 2007 ) is that long run residuals of the cointegrating regression are non stationary.

Results are reported in Table 6 : in the column named $p$-value we report the probability of accepting the null hypothesis of no cointegration with standard critical values (without correction for cross sectional dependencies). The column named robust p-value instead reports the probability of accepting the null of no cointegration, using bootstrapped critical values, which also in this case are calculated as they may take care of potential cross sectional dependencies. From the table we observe that the standard statistics accept the null of no cointegration six times out of eight for the total economy, and three times out 
of eight for the manufacturing sector, at 5 per cent significance. On the contrary, if we look at robust p-values we can never reject the null of no cointegration (all 16 cases): results of the Breusch-Pagan LM test(Breusch and Pagan, 1980) confirm the presence of cross sectional dependence among the countries in the panel and consequently ensures the appropriateness of the use of bootstrapped critical values as appropriate statistics to verify panel cointegration in this case.

We also conducted the likelihood-based panel cointegration test proposed by Larsson et al. (2001), that is based on the average of the individuals trace statistics standardized with asymptotic moments. The null hypothesis of this test is constructed in the same way of Johansen (1988) test, and under the null the statistics is distributed as a normal standard. Results of this test are reported in Table 7. In order to calculate the Larsson statistics, we needed to compute the average of trace statisics of the individual countries, and use the asymptotic mean and variance as in Breitung (2005) that we report in the table. The resulting statisics is reported in the Table in the row where Larsson statistics is indicated. The value of the statistics in the case of $r=0$, corresponds to the case when the cointegration rank is zero. As the statistics in this case is 27.11 , which is larger than the corresponding critical value at 95 per cent, we can reject the hypothesis of rank zero of the cointegration matrix. The procedure considers then the hypothesis of cointegration rank equal to one: given the results we can also reject the hypothesis that the cointegrating rank is 1 (value of the statistics 4.36). The same result holds for Model 2. Consequently, according to the result of this test, we cannot identify the presence of panel cointegration in the countries considered. In the case when cross sectional dependency is taken into account, boot strapped critical values are calculated and the interval is reported in the table $^{10}$. There is 95 per cent of probability that the statistics lays in the interval reported in square brackets, which tells us that the hypothesis of cointegration is rejected also in the case when bootstrapped critical values are considered.

On the whole, the tests reject the hypothesis of a common cointegrating rank among the

${ }^{10}$ The procedure to obtain the bootstrapped interval has been obtained adapting the procedures written by Vinod and da Lacalle (2009) and using the R package 'meboot' 
countries of the euro are and indicate that the hypothesis of no panel cointegration can be accepted at high probability levels, when cross sectional dependency is considered, whose presence we have verified with the use of Breusch-Pagan LM test(Breusch and Pagan, 1980). Thus the panel cointegration analysis casts further doubts over the convergence and ultimately sustainability of diverging dynamics of national ULC within the euro area.

\section{$5 \quad$ Concluding remarks}

We analyse ULC dynamics in the total economy and the manufacturing sector, trying to give an insight on the long-run sustainability of the monetary union. Our analysis shows that euro area countries are characterized by diverging tendencies in ULC dynamics which result in persistent differences in competitiveness, which have increased rather than decreased with the introduction of a common currency. This finding is true for the economy as a whole but even more for the manufacturing sector.

This result is in line with the findings of Belke and Dreger (2011) which stress the increase in competitiveness imbalances in member countries since the introduction of the monetary union, emerging through strongly heterogeneous current account deficits. They suggest that these imbalances originate from competitiveness idiosyncracies, where they measure competitiveness with ULC, as we do. They consequently suggest a policy of reduction of ULC in those countries with lower competitiveness.

We suggest a different interpretation of ULC imbalances in the euro area. In order to do so, we explore the variability of the components of ULC- wage and productivity components - and explore its dynamics. We find out that heterogeneity is indeed larger in productivity rather than in wage compensation, and much strongly for the manufacturing sector than for the total economy. Moreover the trend is increasing in particular in the recent years.

We may interpret these results suggesting that the monetary union has generated real exchange rate appreciation that has reduced competitiveness of countries more specialized in low value added production. This effect has generated current account deficits that 
have created in the long run a spiral of competitiveness loss for these countries, also due to international competition much more fierce for these types of products.

Our results are in line also with the findings of Fischer (2007) which find ULC inflation divergence in the manufacturing sector in the years following the monetary union and similarly identify a pattern of loss of competitiveness of some countries with respect to Germany in particular.

Although the industrial sector is generally more prone to competition in prices, costs convergence almost never guarantees automatic convergence of productive dynamics, ultimately of technological trajectories(Dosi, 1988).

In order to test this hypothesis, a more specific analysis of the situation of industrial competitiveness disaggregated at the sectoral level would be required, but this goes beyond the scope of the present analysis.

We believe nonetheless that this contribution suggests a step up in the policy tasks of the union, plannig common industrial policies with a look at guaranteeing a sustainable competitiveness relationship among members. 


\section{References}

Arthur, W. B. (1989, March). Competing technologies, increasing returns, and lock-in by historical events. Economic Journal 99(394), 116-31.

Baumol, W. J. (1986). Productivity growth, convergence, and welfare: What the long-run data show. The American Economic Review 76(5), 1072-1085.

Belke, A. and C. Dreger (2011). Current account imbalances in the euro area: Catching up or competitiveness? Technical report.

Bertola, G. (2008, November). Labour markets in emu - what has changed and what needs to change. CEPR Discussion Papers 7049, C.E.P.R. Discussion Papers.

Breitung, J. (2005). A parametric approach to the estimation of cointegration vectors in panel data. Econometric Reviews 24(2), pp. 151-173.

Breusch, T. S. and A. R. Pagan (1980). The lagrange multiplier test and its applications to model specification in econometrics. Review of Economic Studies 47(1), 239-53.

Dosi, G. (1988). Sources, procedures, and microeconomic effects of innovation. Journal of Economic Literature 26(3), pp. 1120-1171.

Dullien, S. and U. Fritsche (2008). Does the dispersion of unit labor cost dynamics in the emu imply long-run divergence? International Economics and Economic Policy 5(3), 269-295.

ECB (2005). Inflation differentials in the euro area: Potential causes and policy implications. Technical Report, $1-30$.

ECB (2007). Speech by Lucas Papademos, vice president of the ECB. The ECB and its Watchers IX, Frankfurt am Main, 7 September 200723.

Engle, R. F. and C. W. J. Granger $(1987,2)$. Co-integration and error correction: Representation, estimation and testing. Econometrica 55, 251-276. 
Fischer, C. (2007). An assessment of the trends in international price competitiveness among emu countries. Deutsche Bundesbank Discussion Paper 8.

Gonzalo, J. and J. Pitarakis (1999). Dimensionality effect in cointegration analysisCointegration, Causality and Forecasting: A Festschrift in Honour of C. W. J. Granger., pp. 212-229. Oxford; New York: Oxford University Press.

Herwartz, H. and F. Siedenburg (2011). To converge or not converge: unit labor cost inflation in the euro area. Empirical Economics, 1-13. 10.1007/s00181-011-0535-3.

Johansen, S. (1988). Statistical analysis of cointegration vectors. Journal of Economic Dynamics and Control 12(2-3), $231-254$.

Johansen, S. (2002). A small sample correction for the test of cointegrating rank in the vector autoregressive model. Econometrica 70 (5), 1929-1961.

Johansen, S. and K. Juselius (1990). Maximum likelihood estimation and inference on cointegration - with applications to the demand for money. Oxford Bulletin of Economics and Statistics 52(2), 169-210.

Juselius, K. (2006). The Cointegrated Var Model, Chapter 6. Advanced Texts in Econometrics, Oxford University Press: Oxford.

Krugman, P. (1991). Increasing returns and economic geography. The Journal of Political Economy $99(3)$, pp. 483-499.

Lamo, A., J. J. Pérez, and L. Schuknecht (2008). Public and private sector wages: comovement and causality. ECB Working Paper 963.

Larsson, R., J. Lyhagen, and M. Lothgren (2001). Likelihood-based cointegration tests in heterogeneous panels. Econometrics Journal 4(1), 41.

Pedroni, P. (1999). Critical values for cointegration tests in heterogenous panels with multiple regressors. Oxford Bulletin of Economics and Statistics 3, $653-670$. 
Perez, J. J. and A. J. Sanchez (2010). Is there a signalling role for public wages? Evidence for the euro area based on macro data. ECB Working Paper 1148.

Salido, J. D. L., F. Restoy, and J. Vallés (2005, 3). Inflation differentials in emu: The spanish case. Documentos de Trabajo.

Shiller, R. J. and P. Perron (1985). Testing the random walk hypothesis : Power versus frequency of observation. Economics Letters 18(4), 381-386.

Stock, J. H. and M. W. Watson (2002). Has the business cycle changed and why? NBER Working Papers 9127, National Bureau of Economic Research.

Tatierska, S. (2008). Ulc dynamics of euro area countries and Slovakia in the long run. Association National Bank of Slovakia WP 6.

Trichet, J. C. (2011). Competitiveness and the smooth functioning of Emu. European Central Bank Speech, 23 February 2011.

Vinod, H. and J. L. da Lacalle (2009). Maximum entropy bootstrap for time series: The meboot R package. Journal of Statistical Software 29(5), pp. 955-978.

Wanhong, W. (1996). Time aggregation and skip sampling in cointegration tests. Statistical Papers 37, 225-234.

Westerlund, J. (2007). Testing for error correction in panel data. Oxford Bulletin of Economics and Statistics $69(6)$, pp. 709-748.

Zemanek, H., A. Belke, and G. Schnabl (2010). Current account balances and structural adjustment in the euro area. International Economics and Economic Policy 7, 83-127. 


\section{Appendix}

\subsection{Graphs and Tables}
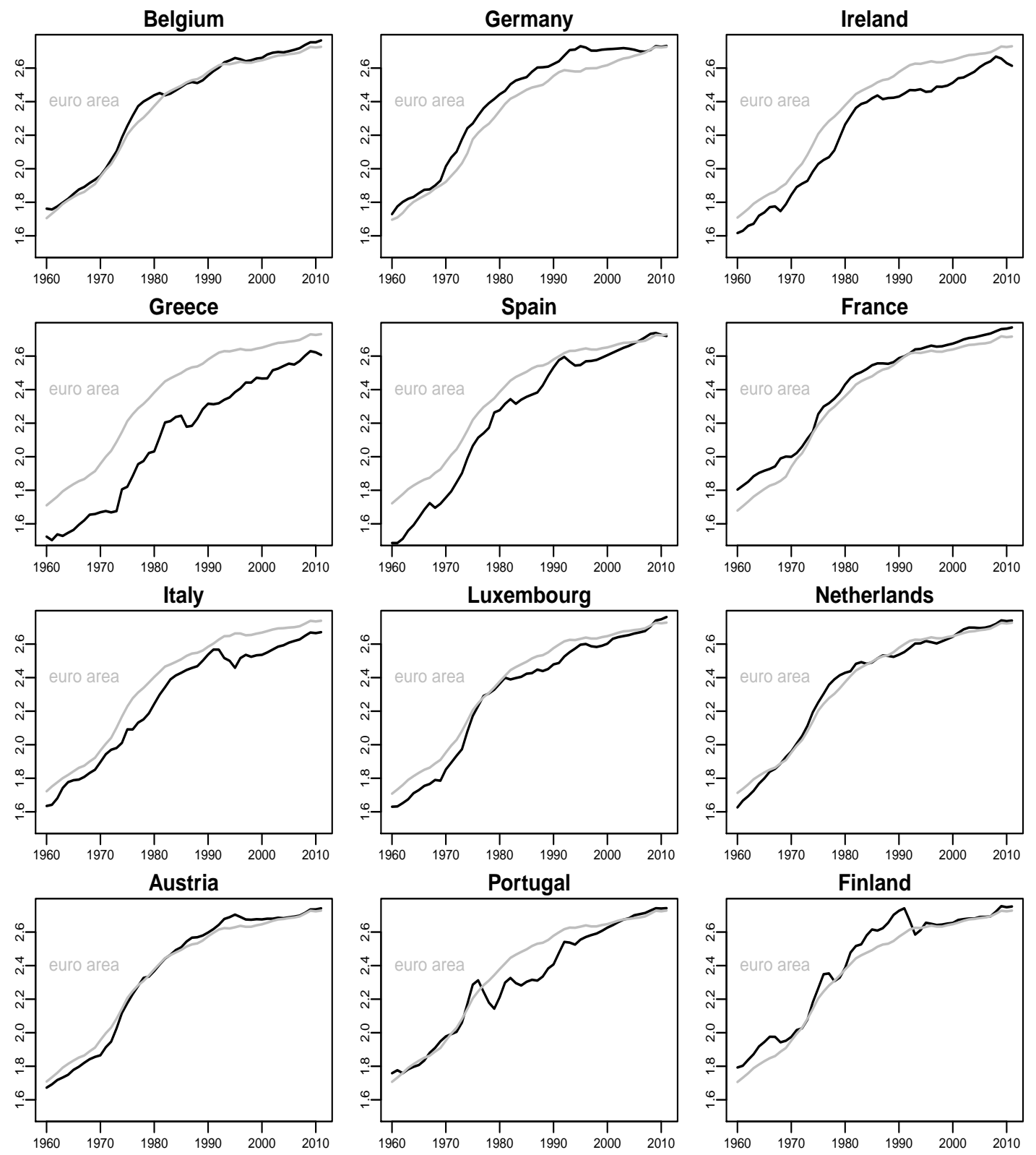

Figure 1: ULC of the total economy in log levels of the i-th country (black line) compared to $\log \mathrm{ULC}$ in levels of the EMU average minus the i-th country (grey line). 

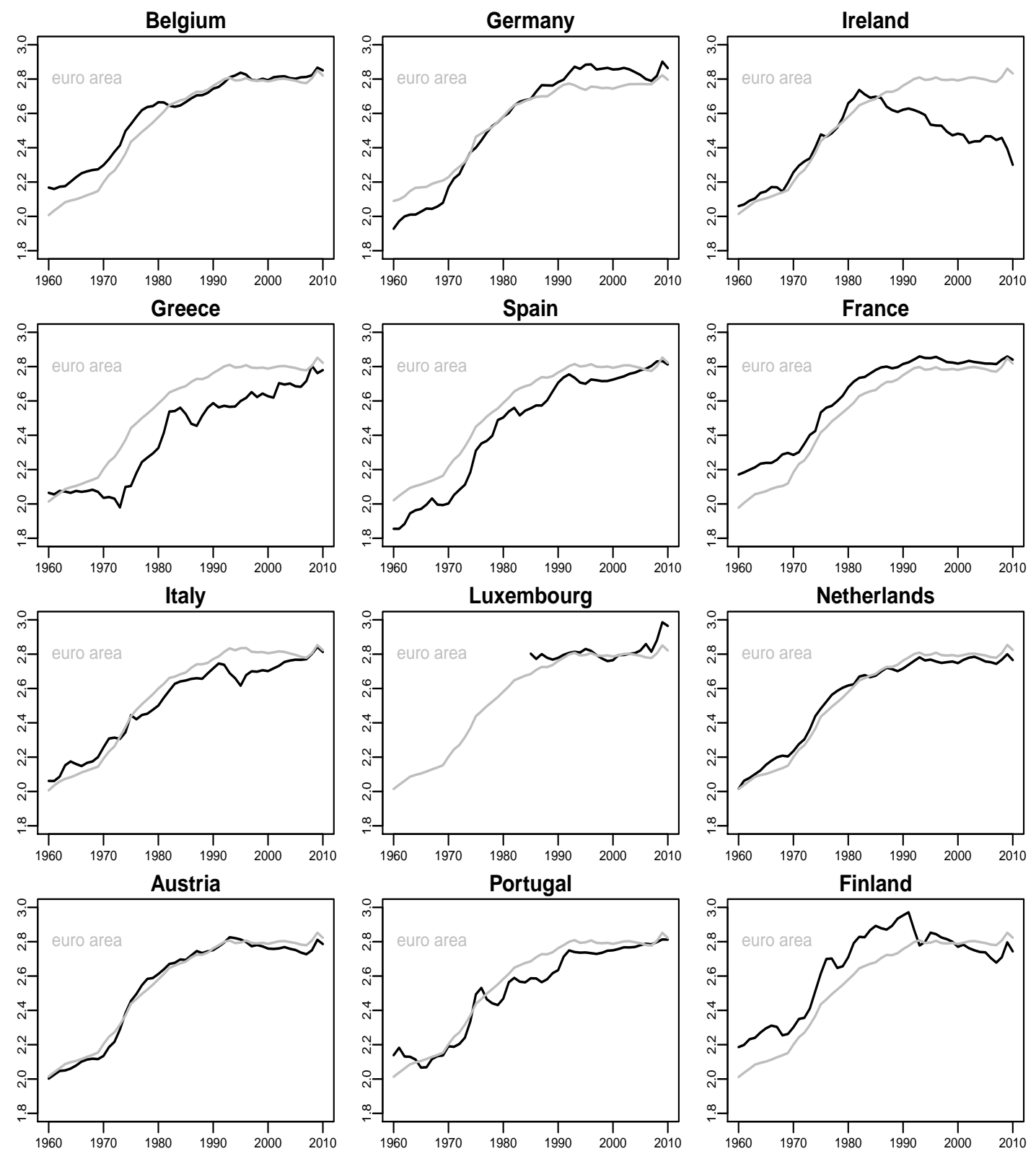

Figure 2: ULC of the manufacturing sector in log levels of the i-th country (black line) compared to $\log$ ULC in levels of the EMU average minus the i-th country (grey line). 

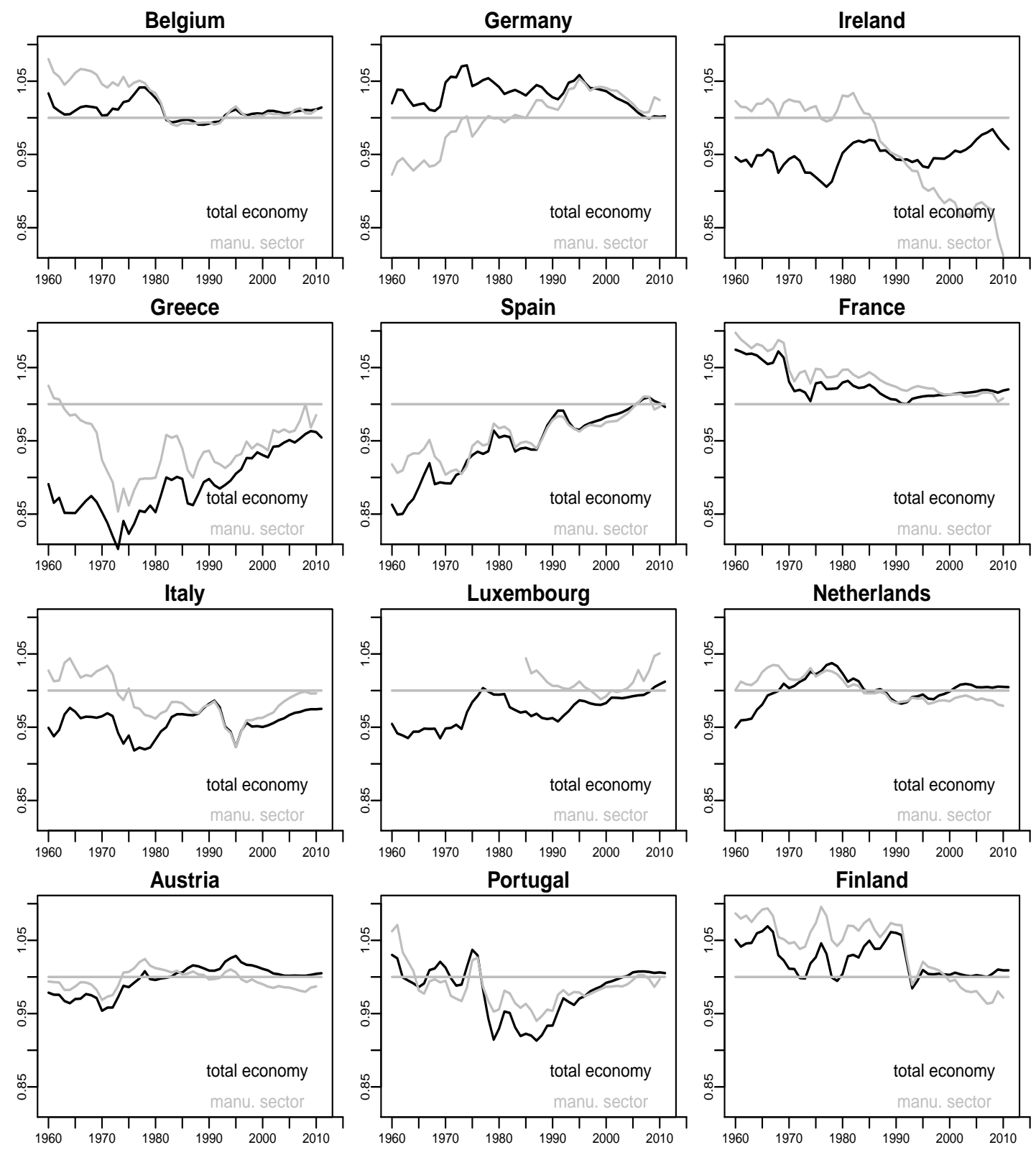

Figure 3: ULC in log levels as a ratio of euro area average minus country i: total economy (black line) and manufacturing sector (grey line). 

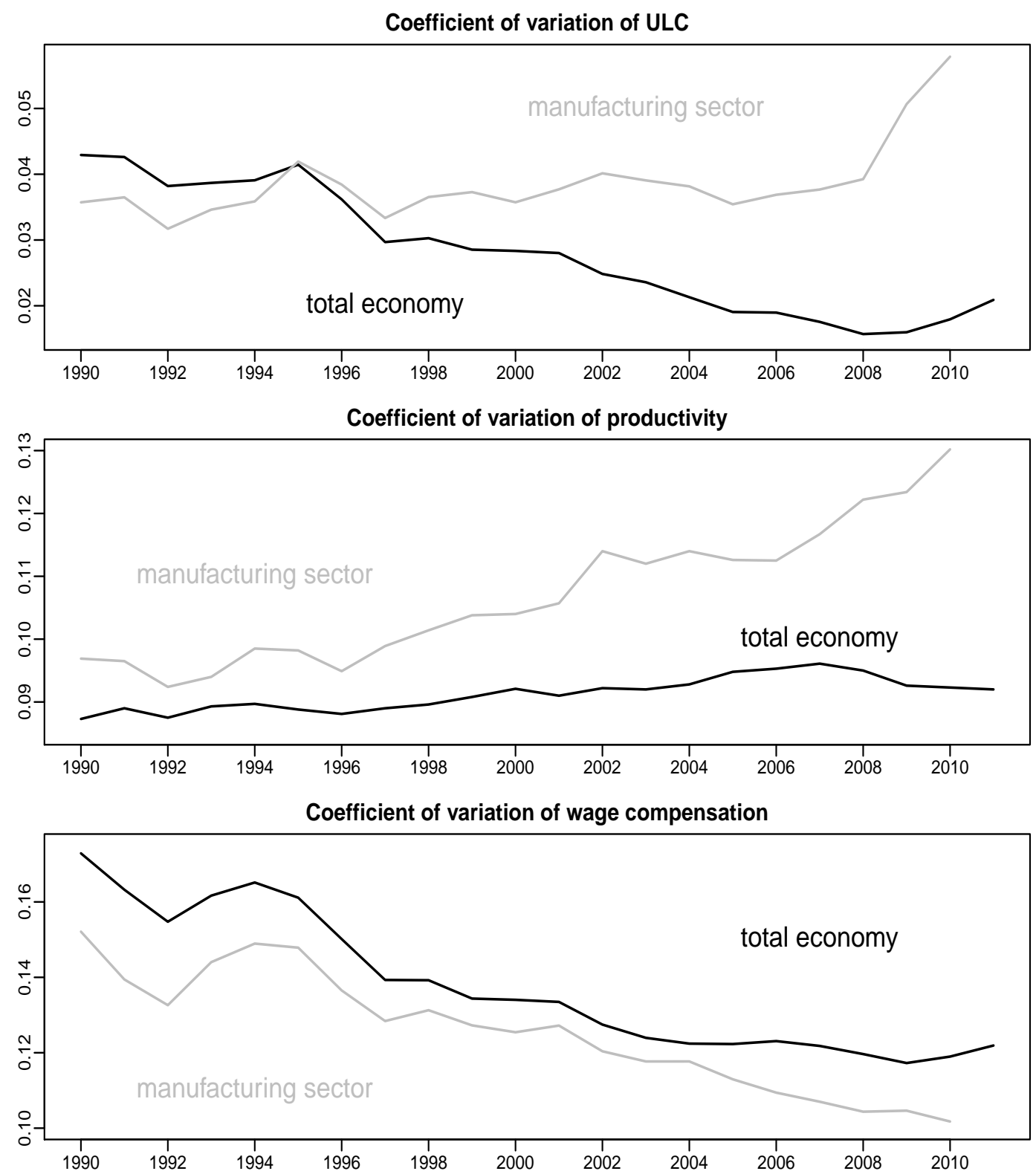

Figure 4: Dispersion of ULC, productivity and wage compensation of euro area members calculated as coefficient of variation for the total economy (black line) and the manufacturing sector (grey line). 

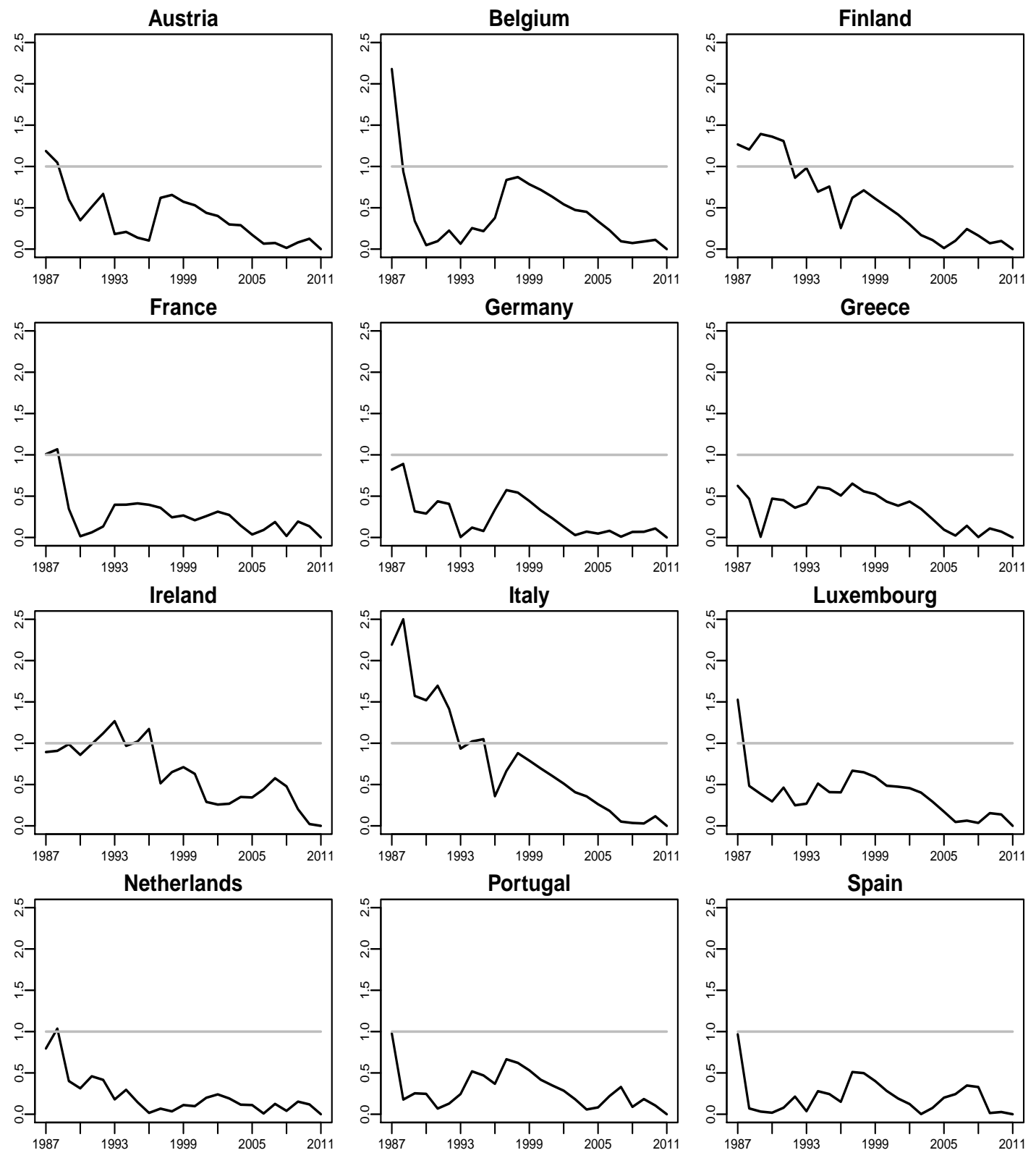

Figure 5: Recursive log likelihood function: total economy 

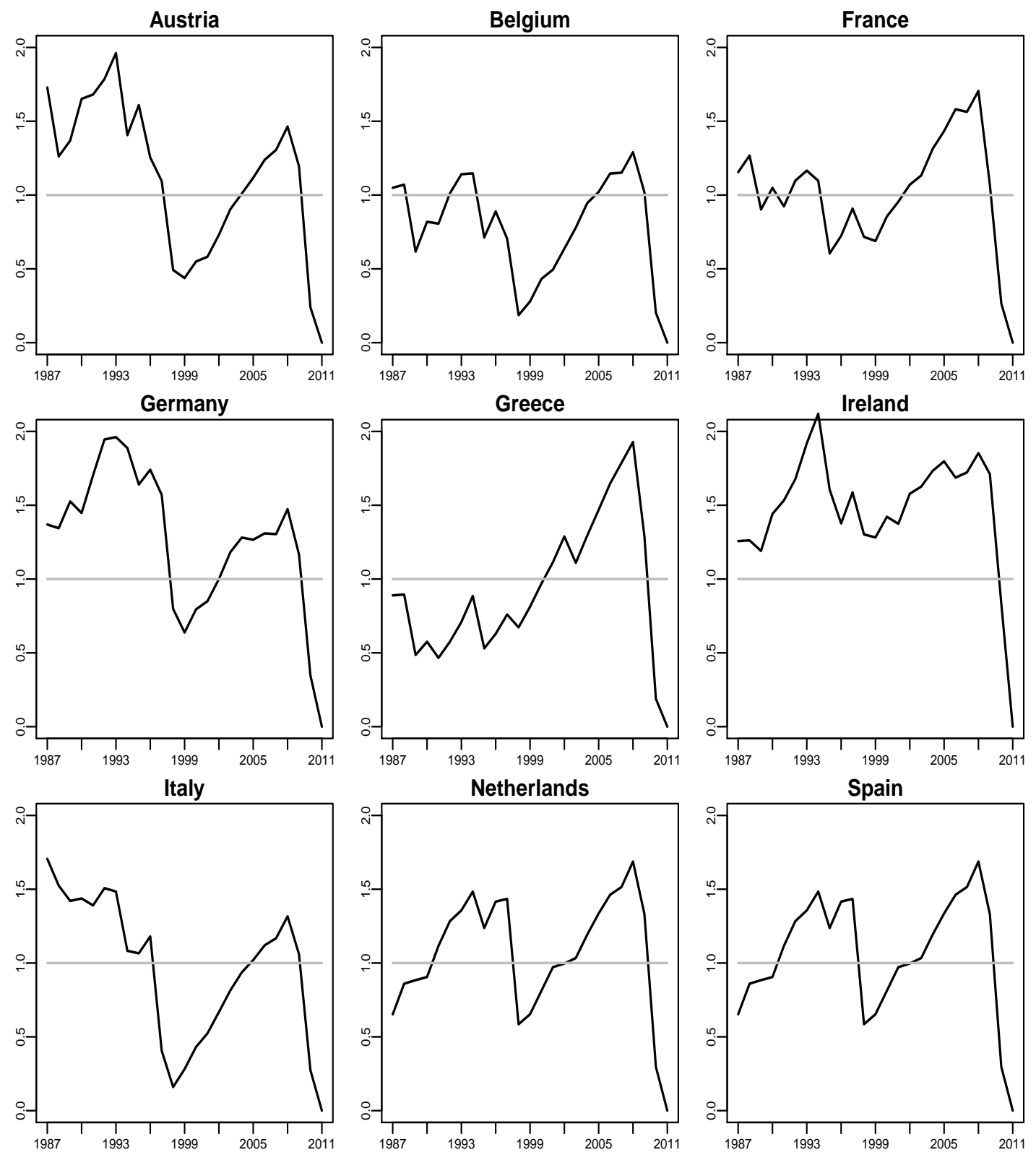

Figure 6: Recursive log likelihood function: manufacturing sector 


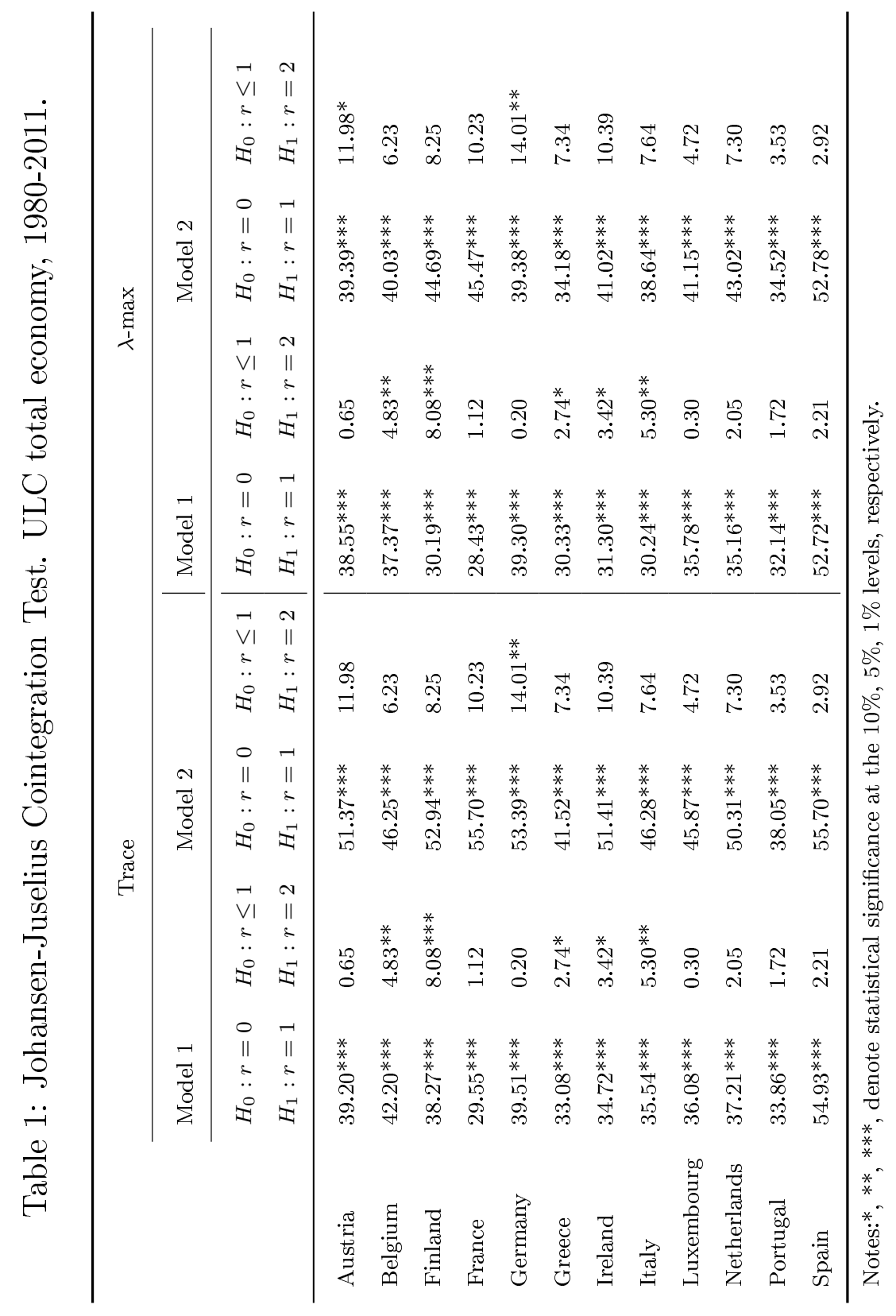




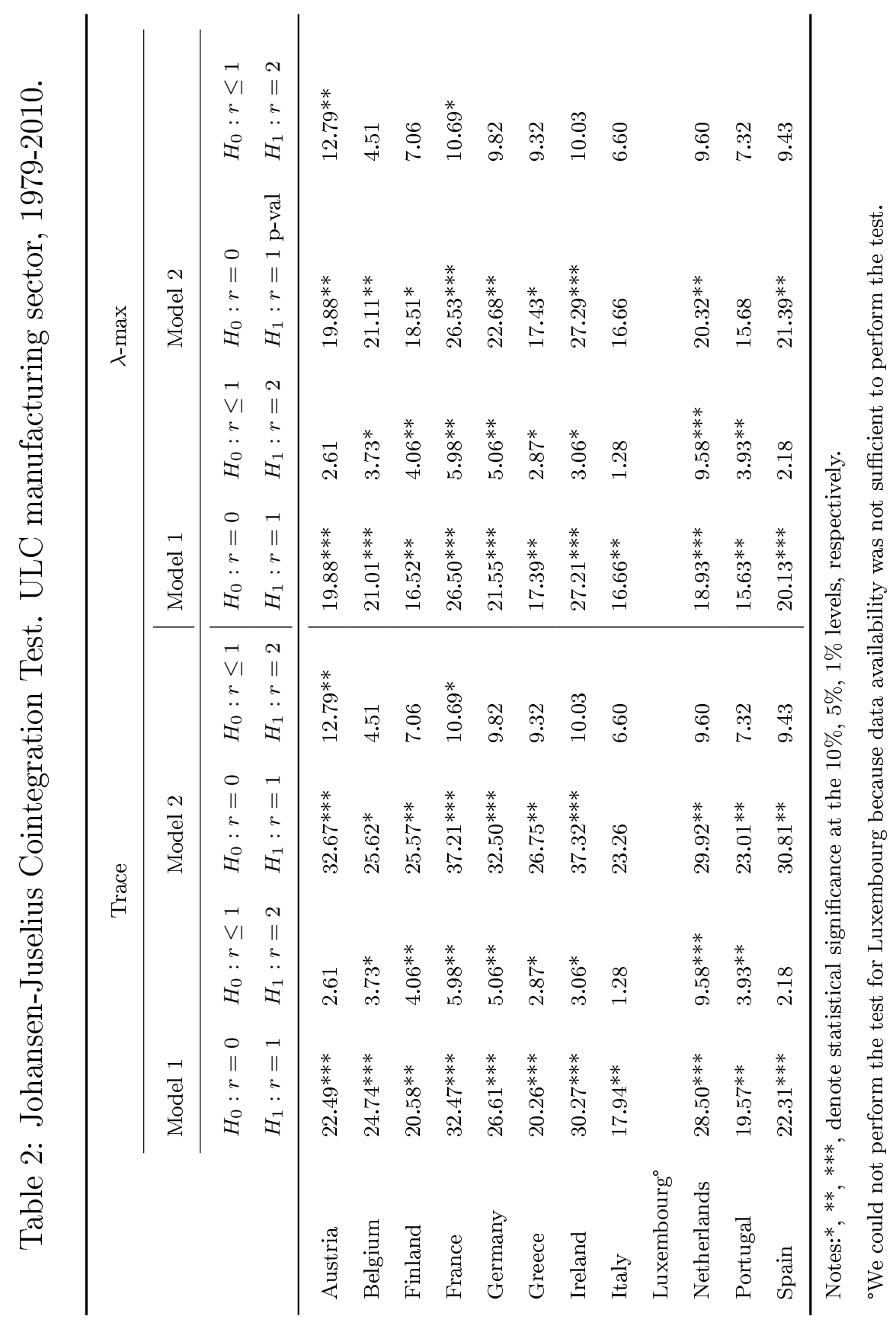


Table 3: Cointegrating Vectors: total Economy and manufacturing Sector.

Total Economy, 1980-2011

\begin{tabular}{|c|c|c|c|c|c|c|}
\hline & Ulc & $\operatorname{UlcEU}\left(\beta_{12}\right)$ & t-stat & Constant $\left(\beta_{14}\right)$ & Trend $\left(\beta_{13}\right)$ & t-stat \\
\hline Austria & 1 & $-0.60 * * *$ & {$[-9.93]$} & -1.07 & - & - \\
\hline Belgium & 1 & $-4.42^{* * *}$ & {$[-6.11]$} & 8.15 & $0.02^{* * *}$ & {$[-6.00]$} \\
\hline Finland & 1 & $-6.47 * * *$ & {$[-7.90]$} & 12.63 & $0.04^{* * *}$ & {$[4.63]$} \\
\hline France & 1 & $-2.20^{* * *}$ & {$[-8.36]$} & 3.07 & - & - \\
\hline Germany & 1 & $-0.29 * * *$ & {$[-4.11]$} & -1.91 & - & - \\
\hline Greece & 1 & $-3.58^{* * *}$ & {$[-12.06]$} & 6.92 & - & - \\
\hline Ireland & 1 & $-3.03^{* * *}$ & {$[-10.44]$} & 5.38 & - & - \\
\hline Italy & 1 & $-16.99^{* * *}$ & {$[-5.68]$} & 38.13 & $0.10^{* * *}$ & {$[3.18]$} \\
\hline Luxembourg & 1 & $-1.94^{* * *}$ & [-17.89] & 2.49 & - & - \\
\hline Netherlands & 1 & $-1.95 * * *$ & {$[-13.86]$} & 2.45 & - & - \\
\hline Portugal & 1 & $-3.33^{* * *}$ & [-13.99] & 6.12 & - & - \\
\hline Spain & 1 & $-2.01 * * *$ & {$[-32.22]$} & 2.68 & - & - \\
\hline \multicolumn{7}{|c|}{ manufacturing Sector, 1979-2010 } \\
\hline & Ulc & $\mathrm{UlcEU}\left(\beta_{12}\right)$ & t-stat & Constant $\left(\beta_{14}\right)$ & Trend $\left(\beta_{13}\right)$ & t-stat \\
\hline Austria & 1 & $0.56^{* *}$ & {$[2.19]$} & -4.28 & - & - \\
\hline Belgium & 1 & $-2.40^{* * *}$ & {$[7.65]$} & 3.82 & - & - \\
\hline \multicolumn{7}{|l|}{ Finland - No coint. } \\
\hline France & 1 & $-0.54^{* * *}$ & {$[-3.38]$} & -1.51 & $0.01^{* * *}$ & {$[3.16]$} \\
\hline Germany & 1 & 0.41 & {$[0.81]$} & -3.73 & 0.00 & {$[-1.26]$} \\
\hline Greece & 1 & $-5.26^{* * *}$ & {$[-6.14]$} & 11.85 & - & - \\
\hline Ireland & 1 & $2.77^{* * *}$ & {$[8.36]$} & -10.16 & - & - \\
\hline Italy & 1 & $-5.16^{* * *}$ & {$[-5.46]$} & 11.55 & - & - \\
\hline Luxembourg - No data & & & & & - & - \\
\hline Netherlands & 1 & $-0.31^{* *}$ & {$[-3.03]$} & -1.84 & 0.00 & {$[-1.21]$} \\
\hline \multicolumn{7}{|l|}{ Portugal - No coint. } \\
\hline Spain & 1 & $-3.06^{* * *}$ & {$[-8.38]$} & 5.74 & - & - \\
\hline
\end{tabular}

Note: $*, * *, * * *$, denote statistical significance at the $10 \%$,

$5 \%, 1 \%$ levels, respectively. T-stats in brackets. 
Table 4: Weak exogeneity test: total Economy and manufacturing Sector.

\begin{tabular}{lllll}
\hline & \multicolumn{2}{l}{ Total Economy, 1980-2011 } & \multicolumn{2}{c}{ Manufacturing Sector, 1979-2010 } \\
\cline { 2 - 5 } & $\chi_{1}^{2}$ & p-value & $\chi_{1}^{2}$ & p-value \\
\hline Austria & $34.17^{* * *}$ & 0.00 & $16.07^{* * *}$ & 0.00 \\
Belgium & $28.77^{* * *}$ & 0.00 & $11.99^{* * *}$ & 0.00 \\
Finland & $32.39^{* * *}$ & 0.00 & No cointegration \\
France & $17.46^{* * *}$ & 0.00 & $21.40^{* * *}$ & 0.00 \\
Germany & $25.34^{* * *}$ & 0.00 & $12.81^{* * *}$ & 0.00 \\
Greece & $27.58^{* * *}$ & 0.00 & $15.50^{* * *}$ & 0.00 \\
Ireland & $29.09^{* * *}$ & 0.00 & $8.77^{* * *}$ & 0.00 \\
Italy & $23.99^{* * *}$ & 0.00 & $14.57^{* * *}$ & 0.00 \\
Luxembourg & $13.08^{* * *}$ & 0.00 & \multicolumn{2}{c}{ No data available } \\
Netherlands & $28.70^{* * *}$ & 0.00 & $17.57^{* * *}$ & 0.00 \\
Portugal & $28.93^{* * *}$ & 0.00 & \multicolumn{2}{c}{ No cointegration } \\
Spain & $48.92^{* * *}$ & 0.00 & $15.82^{* * *}$ & 0.00 \\
\hline
\end{tabular}

Note: $* * *, * * *$, denote statistical significance at the $10 \%, 5 \%, 1 \%$ levels, respectively. T-stats in brackets. 
Table 5: Relative convergence test: total economy and manufacturing Sector.

\begin{tabular}{|c|c|c|c|c|}
\hline & \multicolumn{2}{|c|}{ Total economy, 1980-2011 } & \multicolumn{2}{|c|}{ Manuf. sector, 1979-2010 } \\
\hline & $\chi_{1}^{2}$ & $\mathrm{p}$-value & $\chi_{1}^{2}$ & $\mathrm{p}$-value \\
\hline Austria & $27.48^{* * *}$ & 0.00 & $11.49^{* * *}$ & 0.00 \\
\hline Belgium & $9.02^{* * *}$ & 0.00 & $10.36^{* * *}$ & 0.00 \\
\hline Finland & $26.44^{* * *}$ & 0.00 & \multicolumn{2}{|c|}{ No cointegration } \\
\hline France & $14.92 * * *$ & 0.00 & $6.54^{* *}$ & 0.01 \\
\hline Germany & $39.00 * * *$ & 0.00 & $3.54^{*}$ & 0.06 \\
\hline Greece & $19.39^{* * *}$ & 0.00 & $13.82^{* * *}$ & 0.00 \\
\hline Ireland & $27.56^{* * *}$ & 0.00 & $21.02^{* * *}$ & 0.00 \\
\hline Italy & $19.70^{* * *}$ & 0.00 & $14.46^{* * *}$ & 0.00 \\
\hline Luxembourg & $28.83^{* * *}$ & 0.00 & \multicolumn{2}{|c|}{ No data available } \\
\hline Netherlands & $24.16^{* * *}$ & 0.00 & $5.82^{* *}$ & 0.02 \\
\hline Portugal & $20.41 * * *$ & 0.00 & \multicolumn{2}{|c|}{ No cointegration } \\
\hline Spain & $48.21^{* * *}$ & 0.00 & $17.60^{* * *}$ & 0.00 \\
\hline
\end{tabular}

Note: $*, * *, * * *$, denote statistical significance at the $10 \%, 5 \%, 1 \%$

levels, respectively. T-stats in brackets. 
Table 6: Residual-based panel cointegration test, Westerlund (2007)

\begin{tabular}{lrrrrrr}
\hline & \multicolumn{5}{c}{ Total Economy, 1980-2011 } \\
\hline & No deterministic trend & \multicolumn{2}{c}{ Deterministic trend } \\
& Statistic & P-value & Robust P-value & Statistic & P-value & Robust P-value \\
\hline Panel Gt-Statistic & -1.89 & 0.33 & 0.62 & -2.55 & 0.21 & 0.78 \\
Panel Ga-Statistic & -6.24 & 0.72 & 0.54 & -9.35 & 0.91 & 0.66 \\
Panel Pt-Statistic & -6.44 & 0.08 & 0.46 & -8.15 & 0.17 & 0.68 \\
Panel Pa-Statistic & -7.88 & 0.00 & 0.16 & -12.09 & 0.04 & 0.25 \\
\hline & & & Manufacturing Sector, 1979-2010 & \\
\hline & No deterministic trend & & Deterministic trend & \\
& Statistic & P-value & Robust P-value & Statistic & P-value & Robust P-value \\
\hline Panel Gt-Statistic & -2.31 & 0.03 & 0.36 & -2.87 & 0.02 & 0.72 \\
Panel Ga-Statistic & -7.10 & 0.51 & 0.52 & -11.39 & 0.62 & 0.62 \\
Panel Pt-Statistic & -5.72 & 0.18 & 0.54 & -9.32 & 0.00 & 0.50 \\
Panel Pa-Statistic & -6.36 & 0.06 & 0.37 & -15.11 & 0.00 & 0.13 \\
\hline
\end{tabular}

Note:The null hypothesis $H_{0}$ is of no cointegration. Critical values robust to cross-sectional dependence are obtained by bootstrap, with 1000 replications. 
Table 7: Likelihood-based panel cointegration test, Larsson et al. (2001)

\begin{tabular}{|c|c|c|c|c|}
\hline & \multicolumn{4}{|c|}{ Total Economy, 1980-2011 } \\
\hline & \multicolumn{2}{|r|}{ Model 1} & \multicolumn{2}{|r|}{ Model2 } \\
\hline & $\mathrm{r}=0$ & $\mathrm{r}=1$ & $\mathrm{r}=0$ & $\mathrm{r}=1$ \\
\hline Average of trace statistics & 37.84 & 2.72 & 49.07 & 7.88 \\
\hline Asymptotic mean ${ }^{1}$ & 8.27 & 0.98 & 16.28 & 6.27 \\
\hline Asymptotic variance & 14.28 & 1.91 & 25.50 & 10.45 \\
\hline Larsson et al. (2001) statistic & 27.11 & 4.36 & 22.49 & 1.72 \\
\hline \multirow[t]{4}{*}{ Bootstrapped interval (2) } & [14.46-22.56] & [12.48-20.90] & {$[12.76-22.29]$} & {$[12.75-22.32]$} \\
\hline & \multicolumn{4}{|c|}{ Manufacturing Sector, 1979-2010 } \\
\hline & \multicolumn{2}{|r|}{ Model 1} & \multicolumn{2}{|r|}{ Model2 } \\
\hline & $\mathrm{r}=0$ & $\mathrm{r}=1$ & $\mathrm{r}=0$ & $\mathrm{r}=1$ \\
\hline Average of trace statistics & 24.16 & 4.03 & 29.51 & 8.83 \\
\hline Asymptotic mean & 8.27 & 0.98 & 16.28 & 6.27 \\
\hline Asymptotic variance & 14.28 & 1.91 & 25.50 & 10.45 \\
\hline Larsson et al. (2001) statistic & 13.95 & 7.32 & 8.69 & 2.63 \\
\hline Bootsrapped interval & [8.84-16.38] & [8.85-15.32] & [12.00-20.64] & [12.68-20.78] \\
\hline
\end{tabular}

(1) Asymptotic moments are from Breitung (2005)

(2) $95 \%$ confidence interval simulated with the maximum entropy bootstrap algorithm by Vinod and da Lacalle (2009) with 1000 replications. 


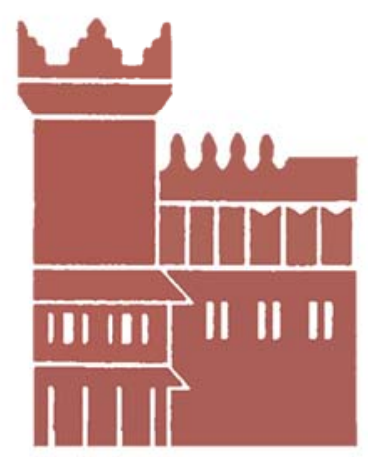

Alma Mater Studiorum - Università di Bologna DEPARTMENT OF ECONOMICS

Strada Maggiore 45

40125 Bologna - Italy

Tel. +39051 2092604

Fax +390512092664

http://www.dse.unibo.it 